\title{
NOTE
}

\section{Recurrent bleaching of corals at Magnetic Island (Australia) relative to air and seawater temperature}

\author{
Ross J. Jones ${ }^{1, *}$, Ray Berkelmans ${ }^{2}$, Jamie K. Oliver ${ }^{2}$ \\ 'Department of Biochemistry, James Cook University, Townsville, Queensland 4811, Australia \\ ${ }^{2}$ Great Barrier Reef Marine Parks Authority, Townsville, Queensland 4810, Australia
}

\begin{abstract}
Coral bleaching events have occurred on the fringing reefs of Magnetic Island (Great Barrier Reef region), Australia, during the summers of $1979 / 80,1981 / 82,1986 / 87$, $1991 / 92$ and 1993/94. Continuous in situ water temperature recordings since 1991 suggest a close correlation between bleaching of corals and periods of average daily seawater temperatures approaching $32^{\circ} \mathrm{C}$. Each of the bleaching events has occurred during periods of unusually high air temperatures, suggesting that 'heat waves' cause a warming of the inshore waters and are a contributory factor in the recurrent bleaching of corals at Magnetic Island. There has been a significant increase in annual summer and winter air temperatures in the Magnetic Island area since the middle of the present century. Significant warming trends have also been observed in the nearby state of Queensland and in Eastern Australia over the same period. Air temperatures similar to those present during the 5 bleaching events which occurred at Magnetic Island have not otherwise been experienced in this area since the 1930 s.
\end{abstract}

KEY WORDS: Bleaching - Coral - Temperature - Climate change

The available evidence suggests that there has been an increase in the number and scale of coral bleaching events (the dissociation of the coral-algal symbiosis) since the early 1980s (Coffroth et al. 1990, Williams \& Bunkley-Williams 1990, Glynn 1993). The extent, timing and severity of many bleaching events have been correlated with positive seawater temperature anomalies (Glynn 1984, Cook et al. 1990, Fitt et al. 1993, Brown et al. 1995, Hoegh-Guldberg \& Salvat 1995). These observations have led to suggestions that we are witnessing the effects of global climate change (Jokiel \& Coles 1990, Williams \& Bunkley-Williams 1990, Glynn 1991).

\footnotetext{
- Present address: School of Biological Sciences, Building A08, University of Sydney, New South Wales 2006, Australia. E-mail: rjones@bio.usyd.edu.au
}

Clear correlations between bleaching events and climate change (regional or local) are scarce, partly because long-term records of recurrent bleaching on reefs, together with accurate records of air and seawater temperatures, are not yet available. One of the best records of recurrent bleaching events comes from the inshore fringing reefs of Magnetic Island (Great Barrier Reef region), Australia, where bleaching events have been observed in the austral summers of $1979 / 80$ (Oliver 1985), 1981/82, 1986/87 (Coffroth et al. 1990), 1991/92 (J. Oliver pers. obs.) and 1993/94 (Jones 1997 in this issue). Seawater temperatures on the reef slope at Magnetic Island have been monitored continuously since late 1991, and air temperature records have been kept since the early part of this century. In this note, the relationship between the bleaching events and mid to long-term seawater and air temperature records is examined.

Materials and methods. Magnetic Island $\left(19^{\circ} \mathrm{S}\right.$ $147^{\circ} \mathrm{E}$ ) is a continental island situated $\sim 8 \mathrm{~km}$ north of the mainland city of Townsville (Queensland, Australia). Seawater temperatures on the reef slope $(5 \mathrm{~m}$ below mean tide level) were measured at Geoffrey Bay (Magnetic Island) from July 1990 to June 1996 by in situ waterproof platinum RTD thermocouple sensors (accuracy $\pm 0.1^{\circ} \mathrm{C}$ ) and recorded onto data loggers [data from the Great Barrier Reef Marine Park Authority, Australian Institute of Marine Science, and Stobart (1994)]. Average daily seawater temperatures over the period were determined from the mean of all half-hourly readings from all available data loggers ( $n=1$ to 3 ).

Long-term air temperature recordings for the Magnetic Island area were obtained from the weather stations at the Townsville Bureau of Meteorology (hereafter TBM, Australian Bureau of Meteorology No. 032040), from 1942 to the present, and the Cape Cleveland Lighthouse (hereafter CCL, Australian Bureau of 
Meteorology No. 032005), from 1927 until records were discontinued in 1987 . The TBM weather station is located on the Australian mainland $\sim 10 \mathrm{~km}$ south of Magnetic Island and the CCL weather station is located on a remote peninsula $10 \mathrm{~km}$ east of Magnetic Island. The average annual summer (October to March), winter (April to September), and daily maximum and minimum air temperatures were determined for all available data. The daily temperature range was also determined from the difference between the daily maximum and minimum air temperatures.

Results and discussion. Widespread bleaching of corals was observed on the reef slopes at Magnetic Island during the summers of 1991/92 and 1993/94. During the bleaching event of $1991 / 92$ average daily seawater temperature exceeded $31^{\circ} \mathrm{C}$ for $14 \mathrm{~d}$, and $31.5^{\circ} \mathrm{C}$ for $2 \mathrm{~d}$ (maximum average daily temperature $=$ $31.7^{\circ} \mathrm{C}$; Fig. 1). These figures must be considered conservative, since no temperature data is available from mid December 1991 to early February 1992 due to failure of the temperature loggers. During the bleaching event of the summer of $1993 / 94$ average daily seawater temperature exceeded $31^{\circ} \mathrm{C}$ for $10 \mathrm{~d}$ and $31.5^{\circ} \mathrm{C}$ for $2 \mathrm{~d}$ (maximum average daily temperature $=31.8^{\circ} \mathrm{C}$; Fig. 1). No bleaching of corals was observed at Magnetic Island during the summers of 1990/91 and 1994/95, when average daily water temperatures exceeded $31^{\circ} \mathrm{C}$ for $5 \mathrm{~d}(1990 / 91$, maximum average daily temperature $\left.=31.2^{\circ} \mathrm{C}\right)$ and $4 \mathrm{~d}(1994 / 95$, maximum average daily temperature $=31.4^{\circ} \mathrm{C}$ ). Average daily seawater temperature in the summers of $1992 / 93$ and $1995 / 96$ did not exceed $31^{\circ} \mathrm{C}$ (Fig. 1), and no significant bleaching of corals was observed at Magnetic Island.

The mid-term temperature record suggests that bleaching of corals is likely to occur at Magnetic Island when average daily seawater temperatures on the reef slope exceed $31.5^{\circ} \mathrm{C}$. It has been established that corals in subtropical and tropical locations are existing very close $\left(1\right.$ to $\left.2^{\circ} \mathrm{C}\right)$ to their upper thermal lethal limit during summer months (Coles et al. 1976). It is now becoming clear from the relationship between bleaching events and seawater temperatures at Magnetic Island (Fig. 1) and in the Indo-Pacific (Brown et al. 1995, Hoegh-Guldberg \& Salvat 1995) that differences in average daily seawater temperatures of $<1^{\circ} \mathrm{C}$ may separate bleaching and non-bleaching years.

The exact start of each of the bleaching events at Magnetic Island has not been determined; however, each event has always been observed in the January through February period, during the height of the austral summer period (J. Oliver pers. obs.). Average air temperatures from January through February (determined from data from both the TBM and CCL weather stations) have exceeded $28.5^{\circ} \mathrm{C} 6$ times since the early 1970 s, and bleaching events have occurred during 5 of these occasions (Fig. 2). A comparison of average January through February air temperatures since 1970 indicates consistent differences between bleaching and non-bleaching years (Mann-Whitney $U$-test, p < 0.05). Given the connection between positive temperature anomalies and coral bleaching events (Fig. 1; Glynn 1984, Cook et al. 1990, Hoegh-Guldberg \& Salvat 1995, Brown et al. 1996), the most persuasive explanation for the recurrent bleaching of corals at Magnetic Island is high air temperatures (heat waves) resulting in localised seawater warming in the shallow reef environment (see also Jones 1997).

Annual air temperature at the TBM has increased by $+0.87^{\circ} \mathrm{C}$ since 1942 (significant at the $5 \%$ level). The increase has occurred through significant changes in

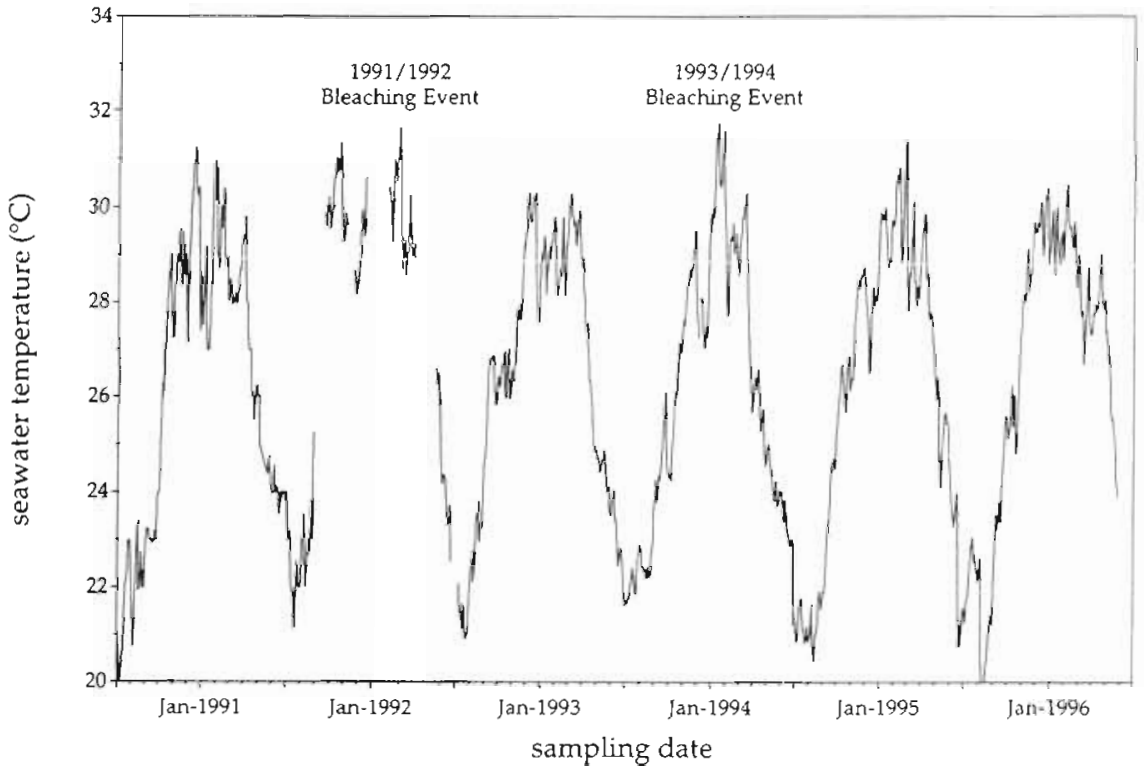

Fig. 1. Average daily seawater temperature from July 1990 to June 1996 at $5 \mathrm{~m}$ depth on the reef slope at Geoffrey Bay (Magnetic Island, Great Barrier Reef region, Australia) Gaps in the data represent failure of the data loggers 


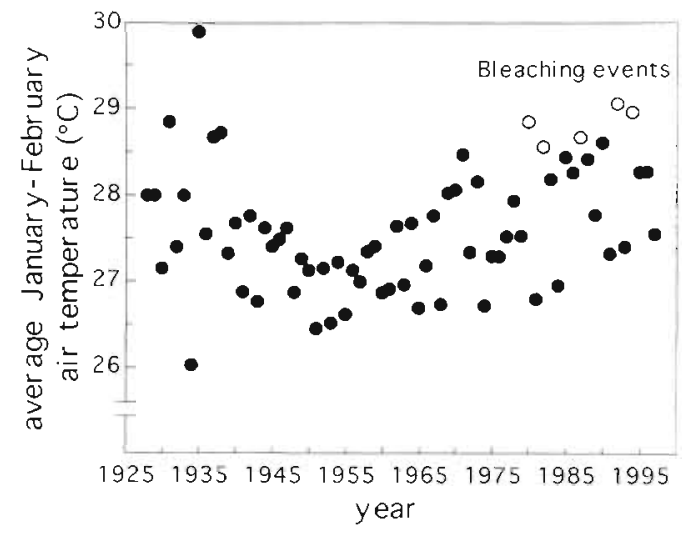

Fig. 2. Average January through February air temperature recorded in the Magnetic Island area from 1927 to 1995. Data from 1927 to 1941 represent recordings at the Cape Cleveland Lighthouse (CCL) weather station only, from 1942 to 1987 a mean of temperature recordings at the CCL and Townsville Bureau of Meteorology (TBM) weather stations, and from 1988 to 1995 recordings at the TBM weather station only. Bleaching events at Magnetic Island are indicated by open circles. The bleaching status of the reefs around Magnetic Island prior to 1970 is unknown

both summer and winter temperatures and through proportionately larger increases in daily minimum than maximum air temperature (Table 1). This 'asymmetric' temperature increase has reduced the average daily temperature range by $-0.52^{\circ} \mathrm{C}$ since 1942 (significant at the $5 \%$ level). Significant warming trends also involving 'asymmetric' temperature increases have been detected in the long-term records of 13 other locations in Queensland (Lough 1995; Table 1) and Eastern Australia (Plummer 1991) as well as in many other parts of the world (Karl et al. 1991, 1993).

Average January-February air temperatures (i.e. the period in which all bleaching events have occurred at Magnetic Island) have increased by $+1.54^{\circ} \mathrm{C}$ since 1942 (significant at the 5\% level; Fig. 2). Temperatures similar to those present during bleaching events at Magnetic Island in recent years have not otherwise been recorded in the local area since the 1930s (Fig. 2). The relationship between bleaching events and periods of elevated air and seawater temperatures (Figs. 1 \& 2), and the absence of similar air temperatures from the late 1930 s until the late 1980s, is suggestive that bleaching events at Magnetic Island are a comparatively recent phenomenon (in the last 25 yr) and are associated with a change in the local climate system. However, it should be noted that air temperatures similar to those experienced during recent bleaching events are not without precedent in the longer term record (Fig. 2).

Long-term water temperature monitoring projects are currently under way at Magnetic Island and may further define the relationship between water temper-
Table 1 Changes $\left({ }^{\circ} \mathrm{C}\right.$ ) in mean annual summer (October to March) and winter (April to September) maximum and minimum air temperatures and in the average daily temperature recorded in the Magnetic Island area (Townsville Bureau of Meteorology, TBM) from 1942 to 1994 and changes in annual maximum and minimum air temperatures and the average daily temperature recorded at the TBM, in Queensland and in Australia (data from Lough 1995) from 1948 to 1987 . Bold type indicates the linear trends are significant at the $5 \%$ level

\begin{tabular}{|llcc|}
\hline Period & \multicolumn{1}{c}{ Area } & Summer & Winter \\
\hline 1942 to 1994 & TBM maximum $T$ & $\mathbf{0 . 8 4}$ & 0.29 \\
1942 to 1994 & TBM minimum $T$ & $\mathbf{1 . 2 8}$ & 1.40 \\
1942 to 1994 & TBM average $T$ & $\mathbf{1 . 0 6}$ & $\mathbf{0 . 8 4}$ \\
1948 to 1987 & TBM maximum $T$ & $\mathbf{0 . 7 6}$ & 0.32 \\
1948 to 1987 & TBM minimum $T$ & $\mathbf{1 . 4 1}$ & $\mathbf{1 . 6 2}$ \\
1948 to 1987 & TBM average $T$ & $\mathbf{1 . 0 9}$ & $\mathbf{0 . 9 8}$ \\
1948 to 1987 & Queensland maximum $T$ & 0.20 & 0.51 \\
1948 to 1987 & Queensland minimum $T$ & $\mathbf{0 . 7 2}$ & $\mathbf{1 . 2 0}$ \\
1948 to 1987 & Queensland average $T$ & $\mathbf{0 . 5 0}$ & $\mathbf{0 . 8 8}$ \\
1948 to 1987 & Australia average $T$ & $\mathbf{0 . 5 4}$ & $\mathbf{0 . 4 6}$ \\
\hline
\end{tabular}

ature, air temperature and the bleaching of corals. Of particular importance is the additive or synergistic effect of irradiance and elevated water temperature, which affects the degree of coral bleaching observed in laboratory studies (Fitt \& Warner 1995) and has not been addressed in this study. Nevertheless, if the current warming trend continues in the Magnetic Island area, further bleaching events are likely to occur. Unless corals can adapt to temperature increases in the short term, possible consequences of these events may include varying degrees of coral mortality and the restructuring of assemblages to more temperaturetolerant species (e.g. Porites spp.) or coral genera which can reach maturity between bleaching events (Hoegh-Guldberg \& Salvat 1995).

Acknowledgements. We thank the Australian Institute of Marine Science for providing temperature data from July 1990 to March 1992 and Ben Stobart who provided temperature data from September 1991 to July 1992

\section{LITERATURE CITED}

Brown BE, Dunne RP, Chansang H (1996) Coral bleaching relative to elevated seawater temperature in the Andaman sea (Indian Ocean) over the last 50 years. Coral Reefs 15: $151-152$

Brown BE, Le Tissier MDA, Bythell JC (1995) Mechanisms of bleaching deduced from histological studies of reef corals sampled during a natural bleaching event. Mar Biol 122: $655-663$

Coffroth MA, Lasker HR, Oliver JK (1990) Coral mortality outside of the eastern Pacific during 1982-1983: relationship to El Niño. In: Glynn PW (ed) Elsevier Oceanography Series. Elsevier, Amsterdam, p 141-182

Coles SL, Jokiel PL, Lewis CR (1976) Thermal tolerance in tropical versus sub-tropical reef corals. Pac Sci 30:159-166 
Cook CB, Logan A, Ward J, Luckhurst B, Berg CJ (1990) Elevated temperatures and bleaching on a high-latitude coral reef: the Bermuda event. Coral Reefs 9:45-49

Fitt WK, Spencer HJ, Halas J, White MW, Porter JW (1993) Recovery of Montastrea annularis in the Florida Keys after the 1987 Caribbean 'bleaching event' Coral Reefs 12:57-64

Fitt WK, Warner ME (1995) Bleaching patterns of four species of Caribbean reef corals. Biol Bull 189:298-307

Glynn PW (1984) Widespread coral mortality and the 1982-1983 El Niño warming event. Environ Conserv 11 $133-146$

Glynn PW (1991) Coral reef bleaching in the 1980's and possible connections with global warming. Trends Ecol Evol $6: 175-179$

Glynn PW (1993) Coral reef bleaching: ecological perspectives. Coral Reefs 12:1-17

Hoegh-Guldberg O, Salvat B (1995) Periodic mass bleaching and elevated seawater temperatures: bleaching of outer reef slope communities in Moorea, French Polynesia. Mar Ecol Prog Ser 121:181-190

Jokiel PL, Coles SL (1990) Responses of Hawaiian and other Indo-Pacific reef corals to elevated temperature. Coral Reefs 8:155-162

Jones RJ (1997) Changes in zooxanthellar densities and chlorophyll concentrations in corals during and after a

Editorial responsibility: Anthony Underwood (Contributing Editor), Sydney, Australia bleaching event. Mar Ecol Prog Ser 158:51-59

Karl TR, Jones PD, Knight RW, Kukla G, Plummer N, Razuvayev V. Gallo KP, Lindseay J, Charlson RJ, Peterson TC (1993) A new perspective on recent global warming: asymmetric trends of daily maximum and minimum temperatures. Bull Am Meteorol Soc 74:1007-1024

Karl TR, Kukla G, Razuvayev VN, Changery MJ, Quayle RG, Heim RR, Easterling DR. Fu CB (1991) Global warming evidence for asymmetric diurnal temperature change. Geophys Res Lett 18:2253-2256

Lough JM (1995) Temperature variations in a tropical-subtropical environment: Queensland, Australia, 1910-1987 Int J Clim 15:77-95

Oliver J (1985) Recurrent seasonal bleaching and mortality of corals on the Great Barrier Reef. Proc 5th Int Coral Reef Congr 4:201-206

Plummer $N$ (1991) Annual mean temperature anomalies over eastern Australia. Bull Aust Meteorol Oceanogr Soc 4: $42-44$

Stobart B (1994) Delimiting coral species using alternative techniques: Montipora digitata (Dana, 1846), a case study. $\mathrm{PhD}$ thesis, James Cook University, Townsville

Williams EH, Bunkley-Williams L (1990) The world-wide coral reef bleaching cycle and related sources of coral mortality. Atoll Res Bull 335:1-71

Submitted: December 1, 1996; Accepted: July 22, 1997

Proofs received from author(s): October 21, 1997 